\title{
Two coexisting heterozygous frameshift mutations in PROP1 are responsible for a different phenotype of combined pituitary hormone deficiency
}

\author{
K. Ziemnicka ${ }^{1}$ - B. Budny ${ }^{1} \cdot$ K. Drobnik ${ }^{1}$ - D. Baszko-Błaszyk ${ }^{1} \cdot$ M. Stajgis ${ }^{2}$. \\ K. Katulska ${ }^{2} \cdot$ R. Waśko ${ }^{1}$ - E. Wrotkowska ${ }^{1}$. R. Słomski ${ }^{3,4}$ - M. Ruchała ${ }^{1}$
}

Received: 25 September 2015 / Revised: 9 November 2015 / Accepted: 12 November 2015 /Published online: 25 November 2015

(C) The Author(s) 2015. This article is published with open access at Springerlink.com

\begin{abstract}
The role of genetic background in childhood-onset combined pituitary hormone deficiency (CPHD) has been extensively studied. The major contributors are the PROP1, POU1F1, LHX3, LHX4 and HESX1 genes coding transcription factors implicated in pituitary organogenesis. The clinical consequences of mutations encompass impaired synthesis of a growth hormone $(\mathrm{GH})$ and one or more concurrent pituitary hormones (i.e. LH, FSH, TSH, PRL). Manifestation of the disorder may vary due to various mutation impacts on the final gene products or an influence of environmental factors during pituitary organogenesis. We describe the clinical and molecular characteristics of two brothers aged 47 and 39 years presenting an uncommon manifestation of congenital hypopituitarism. Sequencing of the PROP1, POU1F1, LHX3, LHX4 and $H E S X 1$ genes was performed to confirm the genetic origin of the disorder. A compound heterozygosity in the PROP1 gene has been identified for both probands. The first change represents a mutational hot spot (c.150delA, p.R53fsX164), whereas the second is a novel alteration (p.R112X) that leads to protein disruption. Based on precise genetic diagnosis, an in
\end{abstract}

Communicated by: Michal Witt

K. Ziemnicka

kaziem@ump.edu.pl

1 Molecular Endocrinology Laboratory, Department of Endocrinology, Metabolism and Internal Diseases, Poznan University of Medical Sciences, 49 Przybyszewskiego Str., 60-355 Poznan, Poland

2 Department of General Radiology II, Poznan University of Medical Sciences, Poznan, Poland

3 Department of Biochemistry and Biotechnology, University of Agriculture, Poznan, Poland

4 Institute of Human Genetics, Polish Academy of Sciences, Poznan, Poland silico prediction of a p.R112X mutation on protein architecture was performed. The resulting clinical phenotype was surprisingly distinct compared to most patients with genetic alterations in PROP1 reported in the current literature. This may be caused by a residual activity of a newly identified p.R112X protein that preserves over $70 \%$ of the homeodomain structure. This examination may confirm a key role of a DNAbinding homeodomain in maintaining $P R O P 1$ functionality and suggests a conceivable explanation of an unusual phenotype.

Keywords CPHD - Combined pituitary hormone deficiency · PROP1

\section{Introduction}

Intensive studies of pituitary organogenesis revealed the indisputable role of transcription factors genes defects in the development of familial combined pituitary hormone deficiency (CPHD). Several mutations have been described within HESX1, LHX3, LHX4, PROP1, POU1F1, PTX and other genes (Romero et al. 2011). Small recurring deletions in the PROP1 gene coding transcription factor taking part in the regulation of pituitary organogenesis are the most common cause of genetically determined CPHD (Böttner et al. 2004; Lebl et al. 2005; Lemos et al. 2006; Voutetakis et al. 2004a). The gene is composed of three highly conserved exons that code for the protein of 226 amino acids residues, retaining the abilities of DNA binding and transcriptional activation (Sornson et al. 1996). Most of these mutations are located within the second exon of the PROP1 gene, although there are some variations of mutations patterns reported for different populations (Kim et al. 2003; McLennan et al. 2003). In more than half of familial CPHD cases, PROP1 gene mutations 
have been identified (Deladoëy et al. 1999). The most common mutation is 301-302delAG and the second is 150delA; other mutations are less frequent. Noticeably lower common frequency of these mutational hot spots was detected among sporadic patients (Turton et al. 2005), supporting the theory of a founder effect mechanism instead of its de novo nature.

PROP1 gene mutations lead to hypopituitarism that is characterised by insufficiency of growth hormone (GH), luteinising hormone ( $\mathrm{LH})$, follicle-stimulating hormone (FSH) and thyroid-stimulating hormone (TSH) synthesis and release. Usually, the first noted symptom is growth failure, and the observed onset encompasses 2 to 8 years of age. The manifestation of central hypothyroidism appears in varying degrees. Typically, in the second decade of life, no sexual maturation is evident and the genitals remain infantile. In some cases of CPHD, usually in the second or even third decades of life, secondary adrenocortical failure develops or a selective DHEA deficiency is seen with normal ACTH-cortisol axis function. In parallel, prolactin deficiency might be present (Flück et al. 1998; Mody et al. 2002; Voutetakis et al. 2001).

The aim of the present work was to evaluate the genetic background of CPHD in two brothers with unusual manifestation of a disorder and to describe the uncommon phenotype.

\section{Patients and methods}

\section{Patients}

Patient 1 was born to parents of normal height after a full-term pregnancy without any complications; his physical and mental development was normal in the first 5 years of life without marked growth disturbances [ -1.0 standard deviation (SD)]. When the patient was 6 years old, his parents noted growth deficiency, pallor of the skin and marked facial oedema. The paediatrician suspected hypothyroidism that was seemingly supported by hypercholesterolaemia and lowered serum thyroid hormone concentrations: total T4 was $0.8 \mu \mathrm{g} / \mathrm{dL}$ (normal range: 4-12) and total T3 was $76 \mathrm{ng} / \mathrm{dL}$ (normal range: 80 200). At that time, analysis of the TSH concentration was not available. The paediatrician commenced levothyroxine therapy. Following this treatment, the patient showed improvement and oedema regressed; however, the linear growth rate was deficient (-2.7 SD). His mental development was normal and he had no learning difficulties at school. At the late age of puberty, signs of sexual maturation were not present and the patient was referred to the Department of Endocrinology, where, based on the hormonal test results, a diagnosis of childhood-onset CPHD (deficiency of GH, TSH and LH/ FSH) was made. At that time, computed tomography (CT) scan of the pituitary area revealed the presence of a hyperdense mass (the density of which did not increase after contrast administration) in a markedly enlarged sella. That lesion was surrounded by fluid. Magnetic resonance imaging (MRI) performed during the next medical evaluation (12 years later) showed remnants of the pituitary gland with a height of about 5-6 $\mathrm{mm}$ and a hypodense lesion (about $6 \mathrm{~mm}$ in diameter) between the anterior and posterior lobes not enhanced with contrast and localised at the left side of the gland. The patient was treated with long-acting testosterone derivatives and levothyroxine (treatment with growth hormone was not available at that moment). He felt well and his growth rate slowly advanced. even in the third decade of life. At the age of 34 years, radiograms of the hands, hips and femurs revealed that epiphyseal fusion did not occur.

Patient 2 was born 8 years after patient 1 . At birth, his weight, length and body proportions were normal. His physical and mental development, in the first four years of life, had a normal course. When he was 4 years old, a mild slowing of the growth rate was noticed $(-1.5 \mathrm{SD})$; the stunted growth was more evident when the patient started his school education at the age of 7 years $(-2.0 \mathrm{SD})$. He was referred to the paediatrician who, in the case history, described skin dryness, puffiness of the face and extremities, increased cholesterol level in the blood and diagnosed hypothyroidism, suspecting a similar problem as in the case of his older brother. The detailed information about his hormone levels at that moment was not available to us. The patient was then treated with levothyroxine and anabolic steroid medication (methandienone, $5 \mathrm{mg}$ daily) to stimulate the stunted growth. This therapy was irregularly continued for several years and resulted in improvement of the patient; however, signs of sexual maturation did not appear and his growth was still deficient $(-2.1 \mathrm{SD})$. At 15 years of age, he was intermittently treated with testosterone enanthate $100 \mathrm{mg}$ intra-muscularly every 2 weeks and $100 \mu \mathrm{g}$ of levothyroxine daily for several years, resulting in slow linear growth rate (even past the age of 20 years), but only slight sexual improvement.

Both brothers were treated and remained under the control of a local endocrinologist. The serum hormone levels were reevaluated at ages of 47 years for patient 1 and 39 years for patient 2, when they were referred to the Department of Endocrinology, Metabolism and Internal Diseases, Poznan University of Medical Sciences, Poland to establish the treatment direction after a long period of irregular hormone replacement therapy.

\section{Hormonal assays and tests}

On the patients' re-evaluations, the basal and stimulated serum GH levels were measured by an immunoradiometric assay (IRMA; DSL Inc., Webster, TX, USA). The GH response in each patient was assessed during insulin-induced hypoglycaemia $(0,1 \mathrm{IU} / \mathrm{kg}$; Actrapid insulin, Novo Nordisk, Denmark). The serum IGF-1 concentration was estimated using SM-C-RIA-CT kits (BioSource, Nivelles, Belgium). 
TSH, fT4, prolactin, cortisol, DHEA-S, LH, FSH and insulin were measured by an immunochemiluminometric assay (ICMA; Roche Diagnostics Elecsys 2010, Basel, Switzerland). The serum ACTH level was assessed by immunoradiometric assay (B.R.A.H.M.S., Hennigsdorf, Germany) and free testosterone was evaluated using RIA kits (DPC, Monroe, LA, USA). The pituitary-adrenal axis was evaluated using insulin-induced hypoglycaemia according to standard procedures, considering normal adrenal response when the cortisol level was over $550 \mathrm{nmol} / \mathrm{L}$. Beside basic levels, TSH and prolactin were also estimated in the TRH stimulation test $(200 \mu \mathrm{g}$ Protirelin i.v., Merck, Darmstadt, Germany). The LH/FSH response was investigated using the GnRH test (100 $\mu \mathrm{g}$ GnRH, Ferring, Germany).

\section{Radiological imaging}

Pituitary MRI was performed using the spin-echo technique in T1-weighted coronal and sagittal scans. Patient 1's sagittal T1weighted pituitary images were performed with a Siemens MAGNETOM Avanto and acquired using multi-slice spinecho pulse sequences with parameters of 800/15/4 (TR/TE/ excitations), 3-mm slice thickness with 1-mm interslice gap, $256 \times 256$ acquisition matrix and a $24-\mathrm{cm}$ field of view. Scans for patient 2 were performed with a Siemens $1 \mathrm{~T}$ MAGNETOM Impact using multi-slice spin-echo pulse sequences with 500/12/4 (TR/TE/excitations), 3-mm slice thickness with $1-\mathrm{mm}$ interslice gap and a $184 \times 210$ acquisition matrix. Coronal T1-weighted images were also obtained with a field of view of $20 \mathrm{~cm}$ for both patients. Radiograms of the skull were evaluated in the sagittal and coronal planes, with the sella turcica length measurement expressed as a distance from the tuberculum sellae to the posterior clinoid (Andredaki et al. 2007).

\section{Molecular screening of CPHD genes}

Blood samples were collected from both brothers. Genomic DNA was extracted from peripheral blood leukocytes according to standard procedures (GTC method). Mutation scanning was carried out by polymerase chain reaction (PCR) and following sequencing of the PCR products. The entire coding sequence of PROP1, POU1F1, LHX3 and LHX4 was amplified, as well as neighbouring exons' intronic sequences (at least 50 nucleotides of each intron-exon boundary). The sequence of PROP1 primers for PCR reaction was used according to those previously published: for the first exon by Deladoëy et al. (1999) and for the second exon by Rosenbloom et al. (1999). For the third exon, a nested PCR was utilised with a new primer pair that was designed on the basis of the $P R O P 1$ genomic sequence. Primer sequences for POU1F1, LHX3, LHX4 and HESX1 were designed using the Primer3 algorithm (http://bioinfo.ut.ee/primer3-0.4.0/).
Genomic sequences for all mentioned genes were recovered from GeeBank. All primer sequences for PCR are given in Table 1.

Amplifications were conducted with the use of the FailSafe $^{\text {TM }}$ PCR PreMix J System (Epicentre, Illumina) and processed through 35 cycles $\left(30 \mathrm{~s}\right.$ at $94{ }^{\circ} \mathrm{C}, 30 \mathrm{~s}$ at $62^{\circ} \mathrm{C}$ and $45 \mathrm{~s}$ at $72{ }^{\circ} \mathrm{C}$ ). All fragments were then subjected to Sanger sequencing on both strands. Capillary sequencing was conducted with the use of BigDye chemistry version 3.1 on an ABI 3130xl DNA Analyzer, according to the manufacturer's instructions (Applied Biosystems, Foster City, CA, USA). Samples were processed through 30 cycles of amplification consisting of $30 \mathrm{~s}$ at $94{ }^{\circ} \mathrm{C}, 30 \mathrm{~s}$ at $60^{\circ} \mathrm{C}$ and $45 \mathrm{~s}$ at $72{ }^{\circ} \mathrm{C}$. The final step was lengthened to $7 \mathrm{~min}$.

Analysis of sequence tracks was achieved with the use of CodonCode Aligner software version 4.0.4 (http://www. codoncode.com). Patients were also screened for structural rearrangements in the PROP1, POU1F1, LHX3, LHX4, $H E S X 1$ and, additionally, GH1 and GHRHR genes using the multiplex ligation-dependent probe amplification (MLPA) method. MLPA reaction was performed using SALSA MLPA P216 Growth Hormone Deficiency mix -1 from MRC-Holland (Netherlands), according to the manufacturer's instructions. This kit contains probes for all exons of the mentioned genes except for exon 2 of $G H 1$, exon 5 of POUIF1 and exon 8 of GHRHR. The amount of genomic DNA used for the MLPA analysis was $200 \mathrm{ng}$. PCR products were separated on an ABI 3130x1 Capillary Sequencer (Applied Biosystems). Data were normalised intra-sample by dividing the peak area of each probe's amplification product by the total area of only the reference probes in the probemix. Intra-sample normalisation was achieved by dividing the intra-normalised probe ratio of all reference samples. Data normalisation was performed within one experiment (MRCHolland). Peak areas in the range $0.7-1.3$ are normal, below 0 . 7 is considered as one copy deletion and above 1.3 for duplication. Each MLPA analysis included several control samples (DNA from healthy individuals).

\section{Bioinformatics approaches}

The identified mutations were checked for correctness of position assessment with the use of the MutationTaster2 program (Schwarz et al. 2010). By employing Bayes classifiers, MutationTaster 2 facilitates prediction of the pathogenicity for an alteration, possible impact of nonsense-mediated decay (NMD) and search for reported variations in the region of novel mutation within selected databases [dbSNP/TGP/ HGMD(public)/ClinVar]. Computation of the PROP1 homeodomain was conveyed with the use of SWISSMODEL (Schwede et al. 2003) and Phyre2 (Kelley and Sternberg 2009), including ten flanking amino acids from both ends. The results were than subsequently compared and 
Table 1 Primer sequences used for PROP1, POU1F1, LHX3, LHX4 and HESX1 screening

Genomic sequence: hg19_chr5:177418235-177424243_rev

\begin{tabular}{|c|c|c|c|}
\hline PROPl & Left primer & Right primer & Product size \\
\hline Exon1 & TTCAGAGACAGAGTCCCAGA & CTCCTAACCTTCTTCATGGA & 326 \\
\hline Exon2 & TGGTCCAGCACCGAGAG & TGCCCAACATTCTATGATAGC & 366 \\
\hline Exon3a & TCTGGCCATGCTGGAGAAG & TTCTAATCGCTGAGCTGAC & 579 \\
\hline Exon3b (nested) & CCCTGCACCTCTTGTCATTGGAGT & AAGCCACCCCATTTTCTTGTCTTT & 492 \\
\hline \multicolumn{4}{|c|}{ Genomic sequence: hg19_chr3:87307782-87326737_rev } \\
\hline POU1F1 & Left primer & Right primer & Product size \\
\hline Exon1 & ATTGAATCGGCCCTTTGAG & GGGTAAAATGAAAGATGCAAAG & 334 \\
\hline Exon2 & CCTACTCGTCAGAGAACTTACCC & TCTGATCACAATTCTTTCAGGC & 358 \\
\hline Exon3 & TGGGCTAAGTCAGGCAAAAC & TCCATAACGACTAACTACGTCCAC & 454 \\
\hline Exon4 & CAGATTTGTGTGACAATGAACC & AАAАССССТСАААССТССТG & 342 \\
\hline Exon5 & CATTCCAACAAAAGTAAAGTGAGG & CTGGGATTATAGGCACCCAC & 538 \\
\hline Exon6 & TGTCCTGCAAGTGTGTTCAG & TGTGAGAAAGAGAGCGGGAG & 632 \\
\hline \multicolumn{4}{|c|}{ Genomic sequence: hg19_chr9:139087095-139097955_rev } \\
\hline$L H X 3$ & Left primer & Right primer & Product size \\
\hline Exon1 & CTCCAGGGGACGCTGAC & АCTTTCTTTGCCTGGCCG & 234 \\
\hline Exon2 & AAGGTGGCTTCACTGCCTC & CTTGGTGATTGTGAGGGGAG & 310 \\
\hline Exon3 & GCTCGGGGCGAAATGAG & GGAGAGAATTTCCCCGGAC & 354 \\
\hline Exon $4 / 5$ & CCTTCCGAGAAGCCTGTG & TCCATGGGAAATTCAGATCC & 642 \\
\hline Exon6 & CAGGATGGGACTCTGAGGG & CCTGGCCCCACTTCCTC & 580 \\
\hline \multicolumn{4}{|c|}{ Genomic sequence: hg19_chr1:180198432-18024518 } \\
\hline LHX4 & Left primer & Right primer & Product size \\
\hline Exon1 & AGCTAGAGCGAGAGAGCGAG & CCCTGTGACCGCCTCTG & 268 \\
\hline Exon2 & TGGTTAGCAGGGCTGTGTG & CTCACTGCTTGGGGAGAGG & 289 \\
\hline Exon3 & GAAGCCAGATCCCTTGCTC & GAGAAGGGCACCTCAGGC & 335 \\
\hline Exon4 & AGGGTGTGGGAGGAGGC & TCACTCAGGATACCTTCCACC & 295 \\
\hline Exon5 & GCTTTGGGTTTGTGGTGG & TCCTGAGTGCCAGGGATTAC & 302 \\
\hline Exon6 & GGGACCATCAGAGTCCTGG & TTCGATCCTTAAAAGGCAAG & 535 \\
\hline \multicolumn{4}{|c|}{ Genomic sequence: hg19_chr3:57230943-57235280_rev } \\
\hline HESX & Left primer & Right primer & Product size \\
\hline Exon1 & CCTATACACGTGGGGCAGAG & TGAAATAAAGGGCAAATTAAACAC & 290 \\
\hline Exon2 & TCCTGAAACTACCTCTATAGAACTTTG & TGCTCAACTTGGTGTCAATTAAAG & 339 \\
\hline Exon3/4 & AGACTACCATATTTTAACAATTTCCAG & CACTGATTCTTCATGCTCTGC & 498 \\
\hline
\end{tabular}

evaluated. Confidence in the models was as follows: 78 residues $(98 \%)$ modelled at $>90 \%$ accuracy for the reference homeodomain and 50 residues $(96 \%)$ modelled at $>90 \%$ accuracy for the p.R112X homeodomain. The protein structures ( $p d b$ files) were subjected to molecular graphics and further analyses with the use of the UCSF Chimera package (Pettersen et al. 2004; Yang et al. 2012).

\section{Results}

Both patients were admitted to the Department of Endocrinology, Poznan University of Medical Sciences after irregular therapy with L-thyroxine and testosterone enanthate for hormonal re-evaluation and imaging study. On physical examination of the 47-year-old patient 1, his height was $152 \mathrm{~cm}(-4.0 \mathrm{SD})$, body proportions normal and his arm span measured $152 \mathrm{~cm}$. He was obese [body mass index (BMI) $30.2 \mathrm{~kg} / \mathrm{m}^{2}$ ]. His head circumference (measured just above the ears and eyebrows level) was $58 \mathrm{~cm}$ (75th percentile), face was pale and bloated with puffed upper eyelids and cheeks, and his nose was broad. His skin was dry, muscles poorly developed and subcutaneous fat tissue was abundant, especially on the abdomen obscuring the waist; fat pads were also present in the supraclavicular areas. There was no beard growth and no body hair, the axillary and pubic and scrotum hair were scanty. His genitals were underdeveloped, the penis and testicles of child-like proportions and his scrotum was 
only slightly pigmented (Tanner stage 2). The results of the hormone assays are listed in Table 2.

Patient 2 was admitted for detailed hormonal investigations when he was 39 years old. On physical examination, his height was $161 \mathrm{~cm}(-2.88 \mathrm{SD})$ and his weight was $65 \mathrm{~kg}$. His body proportions were normal. with an arm span of $161 \mathrm{~cm}$. His head circumference (measured as above) was $59 \mathrm{~cm}$ (over the 90th percentile), and the patient did not present child-like proportions between the vault and face; also, his nose was broad and well developed. His skin was dry, and a slight puffiness was seen on his face and dorsum of the hands. There was no beard growth and sexual hair was scanty. The size of his genitals was like in the pre-pubertal stage (Tanner stage 1) and bilateral cryptorchidism was present.

Lateral skull radiography performed in both brothers revealed thick calvarial bones. The sella was rounded and of increased dimensions (the sella length in patient 1 was $15 \mathrm{~mm}$ and that in patient 2 was $14 \mathrm{~mm}$ ). The dorsum had a vertical position, with no posterior clinoid processes.

\section{MRI findings}

\section{Patient 1}

Pituitary scans revealed a discrete deepening of the sella and reduced mass of the anterior lobe due to the presence of a cyst on the left side with dimensions $6 \times 5 \times 7 \mathrm{~mm}$. All pituitary masses had dimensions as follows: height $5-6 \mathrm{~mm}$, width (coronal plane) $13 \mathrm{~mm}$ and anteroposterior $12 \mathrm{~mm}$. There was no posterior lobe ectopy or pituitary stalk interruption, although the stalk appeared to be thin (1-2 mm) (Fig. 1).

Table 2 Individual blood hormone values in the two studied patients before and after stimulation tests performed during the last hospitalisation (patient 1 at age 47 years and patient 2 at age 39 years)

\begin{tabular}{|c|c|c|c|c|c|}
\hline \multirow[t]{2}{*}{ Hormone } & \multicolumn{2}{|c|}{ Patient 1} & \multicolumn{2}{|c|}{ Patient 2} & \multirow{2}{*}{$\begin{array}{l}\text { Normal range* } \\
\text { (basal evaluation) }\end{array}$} \\
\hline & Basal & Peak & Basal & Peak & \\
\hline $\mathrm{GH}(\mathrm{ng} / \mathrm{mL})$ & 1.1 & 1.3 & 0.5 & 1.3 & $0-10$ \\
\hline IGF-1 (ng/mL) & 23 & - & 56 & - & $90-412$ \\
\hline TSH (mIU/L) & 0.2 & 2.1 & 0.14 & 1.9 & $0.27-4.2$ \\
\hline $\mathrm{fT} 4(\mathrm{pmol} / \mathrm{L})$ & 6.5 & - & 7.1 & - & $11.5-21.0$ \\
\hline LH (mIU/mL) & 0.1 & 1.6 & 0.1 & 1.8 & $1.5-9.0$ \\
\hline FSH (mIU/mL) & 0.1 & 1.9 & 0.1 & 1.7 & $1.5-12.5$ \\
\hline Testosterone (pg/mL) & 2,3 & - & 4,8 & - & $5.6-27.0$ \\
\hline $\mathrm{ACTH}(\mathrm{pg} / \mathrm{mL})$ & 23.0 & 59.7 & 18.1 & 39.5 & $0-50$ \\
\hline Cortisol (nmol/L) & 498.6 & 715.2 & 367.1 & 672.0 & $220-590$ \\
\hline DHEA-S $(\mu \mathrm{g} / \mathrm{dL})$ & 95.3 & - & 55.5 & - & $100-300$ \\
\hline Prolactin (mIU/L) & 86.6 & 109.9 & 43,3 & 45.9 & $85-390$ \\
\hline
\end{tabular}

*The cortisol level was evaluated at 8.00 am
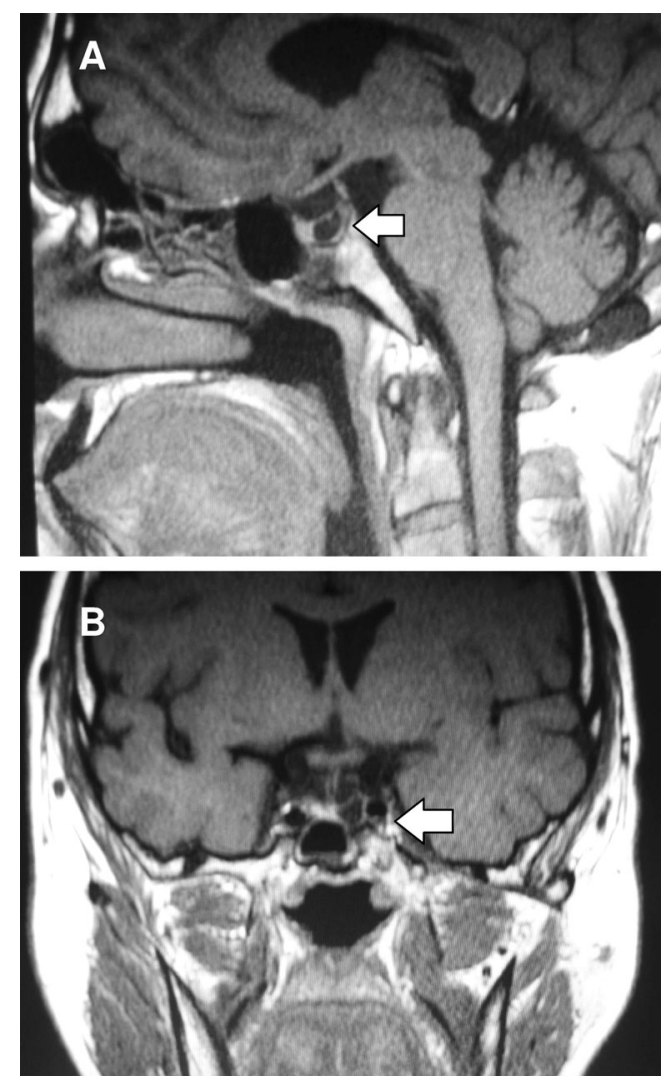

Fig. 1 a Midline sagittal and b coronal magnetic resonance imaging (MRI) sections showing hypoplasia of the pituitary anterior lobe and presence of an anterior lobe cyst in patient 1

\section{Patient 2}

MRI scans revealed pituitary hypoplasia with height $2 \mathrm{~mm}$, width (coronal plane) $11-12 \mathrm{~mm}$ and anteroposterior dimension $10 \mathrm{~mm}$. Like in patient 1 , there was no dislocation of the posterior lobe and no interruption of the pituitary stalk (Fig. 2).

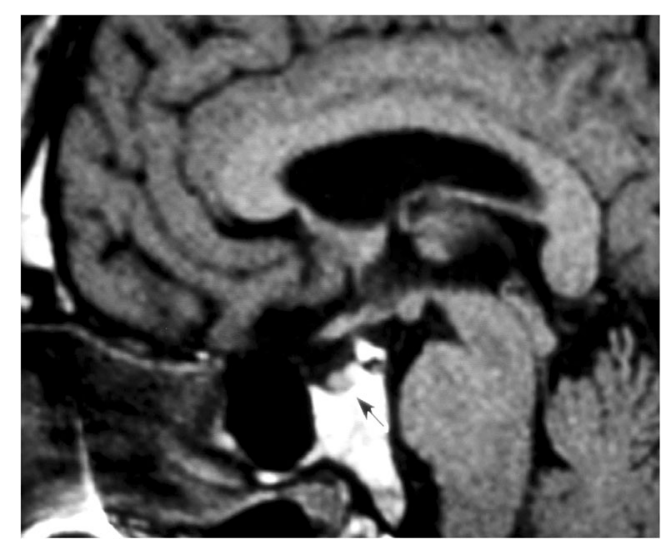

Fig. 2 Midline sagittal MRI section showing hypoplasia of the anterior pituitary lobe in patient 2 . The arrow indicates the small pituitary gland 


\section{Hormonal studies}

Hormonal assays (Table 1) in both patients showed low serum GH level that did not rise during insulin-induced hypoglycaemia and, also, low IGF-1 concentration. The serum-free thyroxine (fT4) level was low, with TSH concentrations below $0.3 \mathrm{mIU} / \mathrm{L}$ and poor response during the TRHTSH test was evident. Serum LH and FSH levels were undetectable and serum-free testosterone was also very low. Serum prolactin was low in patient 2 and normal in patient 1 , and, in both cases, only slightly raised in the TRH stimulation test. Plasma ACTH was in the normal range and serum cortisol was normal, whereas serum DHEA was below the normal range.

\section{Genetic analyses}

Screening for mutations in CPHD genes revealed a compound heterozygosity that occurred in both brothers in the PROPI gene. Two different mutations were identified (c.150delA and novel c.334C $>\mathrm{T}$ transition), and no other significant change in the reference sequence was present (non-synonymous or rare polymorphisms were also excluded). With regards to an inconspicuous phenotype of the parents and another brother (they did not give consent for genetic study, although according to information provided by the patients, their mother's height was $170 \mathrm{~cm}(0.66 \mathrm{SD})$, the father's height was $171 \mathrm{~cm}(-1.3 \mathrm{SD})$ and the other brother's height was $180 \mathrm{~cm}(0.16 \mathrm{SD})$; the abbreviated family pedigree is shown in Fig. 3). We inferred that both alleles carrying mutations were transmitted independently, confirming the recessive inheritance of CPHD. The c.150delA deletion results in a frameshift of the coding sequence, starting at codon 53 and further leading to a premature termination signal at codon 164 (p.R53fsX164). The c.334C $>$ T substitution (Fig. 4) is reported for the first time and causes an amino acid change of arginine

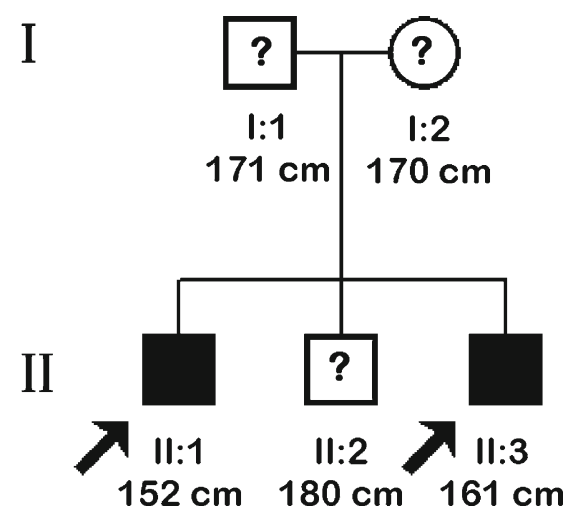

Fig. 3 Abbreviated pedigree of the family with $P R O P 1$ gene mutations. The arrows indicate the individuals examined in this study. Affected males are denoted by black squares (II:1, II:3), while asymptomatic obligatory heterozygotes (I:1, I:2) and an individual with unknown genetic status (II:2) are depicted by question marks to the STOP codon (p.R112X) and, therefore, protein truncation as well. An in silico prediction using MutationTaster2 confirmed significant protein alteration (115 AA missing, $>50 \%$ of the protein sequence) and possible occurrence of the NMD mechanism. Computation of the PROP1 homeodomain with the use of SWISS-MODEL and Phyre2 revealed the lack of the third, most distally located and longest alpha helix folding within the DNA-binding homeodomain, whereas the structure of the two other alpha helices remained intact (Fig. 5). The mutation screening of POU1F1, LHX3, $L H X 4$ and HESX1 did not reveal any other concurrent abnormalities within coding sequences. The MLPA examination focusing on the identification of copy number abnormalities for selected genes did not result in finding any alterations.

\section{Discussion}

CPHD caused by PROP1 gene mutation leads to GH, TSH and gonadotropins deficit, but the course of this disorder may vary, even within a family with the same genetic defect (Flück et al. 1998). The diagnosis of GH deficiency usually precedes those of TSH and LH/FSH, and it happens in more than $80 \%$ of these patients (Deladoëy et al. 1999; Mody et al. 2002). Symptoms of central hypothyroidism and mild growth failure in the first years of life, followed by marked growth deficiency and secondary gonadal insufficiency later in life, prevailed in both of the described patients. Thyroid hormone deficiency was clinically manifested as oedema of the face, neck and extremities, and in biochemical evaluation presented as very low T4 and T3 concentrations and high serum cholesterol. Secondary testicular failure at and past the age of puberty was indicated by the lack of any signs of sexual maturation, no beard or sexual hair growth and infantile genitals with cryptorchidism in one patient. The hormone assays test disclosed very low LH, FSH and testosterone concentrations. Despite a prolonged testosterone replacement therapy, signs of masculinisation appeared to be of limited extent, as the genitals still remained infantile and there was no beard growth. This is typical for most patients with CPHD caused by PROP1 gene defects, but at some points, the clinical manifestation of CPHD in the studied brothers varied. The head circumferences of both patients reached the 75th and 90th percentiles and were typical for 180-cm-tall males, thus differing from other CPHD cases (Bushby et al. 1992; Rosenbloom et al. 1999). Lateral and frontal skull radiographs revealed thick calvarial bones, which may indicate that marked GH deficiency appeared later. The borderline height of patient 2 in the first two decades of life could also support this explanation. Arroyo et al. (2002) reported a unique case of CPHD associated with normal height and absent puberty caused by a PROP1 defect (R120C) also located in the third helix of the PROP1 homeodomain. 
Fig. 4 a Sequence of the second exon of the PROP1 gene showing the $\mathrm{c} .334 \mathrm{C}>\mathrm{T}$ mutation (position of nucleotide change is indicated by an arrow) and $\mathbf{b}$ sequence of a healthy individual as a normal control
A

GCCTCAGTGAGGCCNGAATCCA G T T G A T C T C C

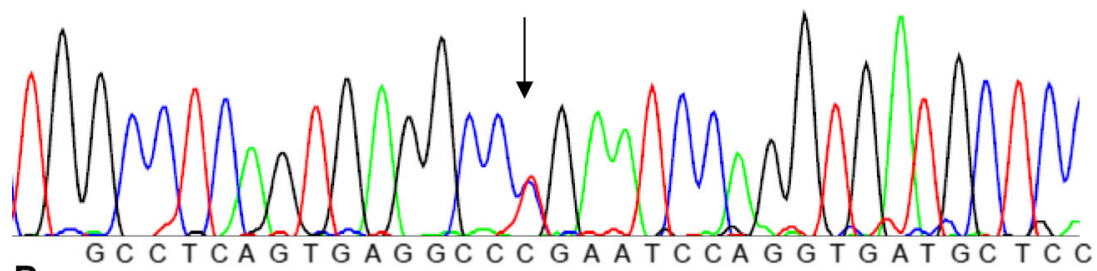

B

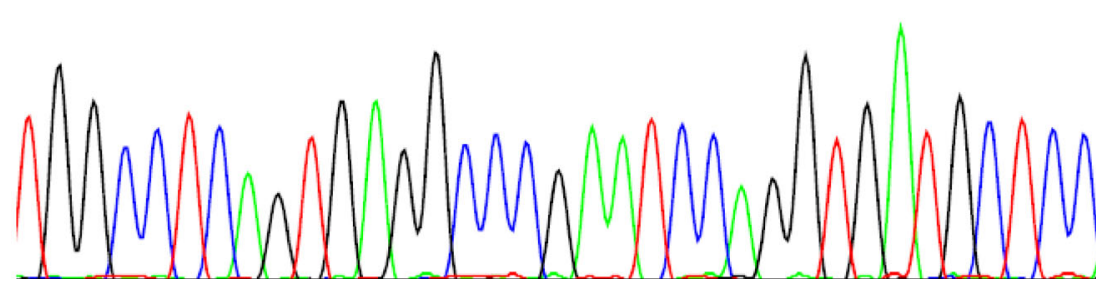

Hypothyroidism as a first sign is not a frequent finding in CPHD patients and appears in subjects affected by different genetic defects. Deladoëy et al. reported hypothyroidism at 3 years of life in $20 \%$ (7 cases) of the studied CPHD patients with PROP1 gene mutations (but the particular PROP1 defects in these cases were not specified) (Deladoëy et al. 1999). Voutetakis at al. also reported on a neonate with a novel PROP1 gene mutation (Q83X) coexisting with previously described 296delGA which led to protein truncation (the protein product was restricted to only 82 of the 226 amino acids) and, therefore, absence of the DNA-binding and transactivation domain of PROP1. A child affected by these mutations presented prolonged jaundice, early manifested central hypothyroidism and pituitary enlargement (Voutetakis et al. 2004b). Flück at al. reported on a girl affected by the R120C PROP1 gene mutation who presented with a lack of TSH shortly after birth and GH deficiency gradually appearing with age. The other family members carrying the same mutation did not present such course of CPHD, mainly showing severe growth retardation as a first sign (Flück et al. 1998). The functional studies of p.R120C substitution done by Wu et al. revealed that similarly altered mouse Prop1 factor possessed reduced DNA-binding activity and presented impaired transactivation ability (Wu et al. 1998). Two young siblings under 2 years of age with 296delGA mutation in the PROP1 gene and isolated central hypothyroidism were also described by Wassner et al. (2013).
A

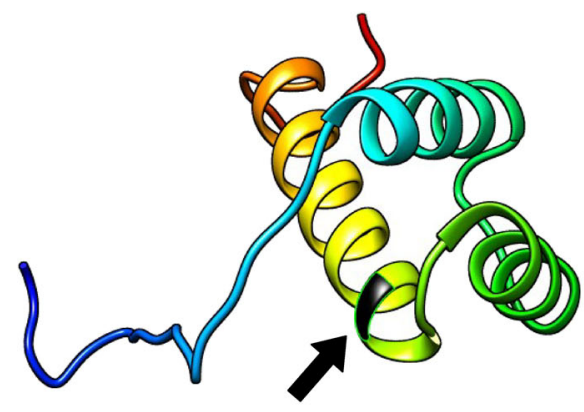

B

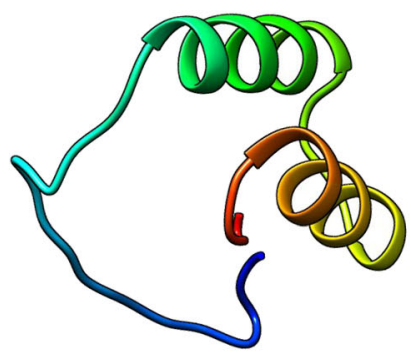

C

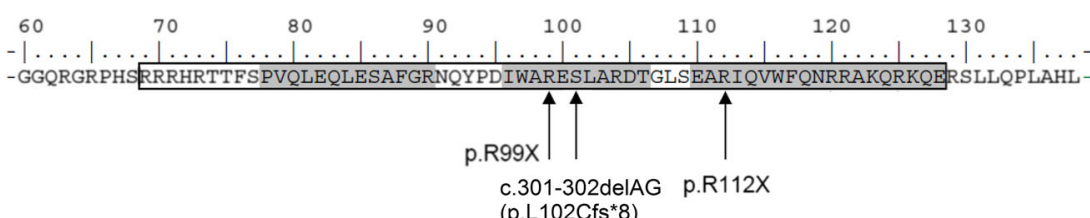

Fig. 5 Modelling of the $P R O P 1$ homeodomain (AA 69-128, framed). a Structural model of the PROP1 homeodomain with depicted position of 112 arginine (arrow). b Prediction of the effect of R112X on the structure, revealing the lack of the third, longest alpha helix folding. $\mathbf{c}$ A string of the selected region in the $P R O P 1$ protein sequence encompassing the homeodomain (framed) with three alpha-helix folding (shaded) and marked novel mutation site. The mutations lead to a similar phenotype p.R99X, c.301-302delAG (p.L102Cfs*8, also referred to as p.S109X) 
The genetic abnormalities found in our reported patients suggest the lack of a functional protein. Both affected copies of the $P R O P 1$ gene in patients lead to impairment of the main functional domain of the protein (frameshift, premature termination signal) and, therefore, production of truncated proteins with 164 and 112 amino acids residues, respectively. The pathogenic impact of the known c.150delA mutation has been well described and evidenced by numerous authors in the current literature (Fofanova et al. 1998; Riepe et al. 2001; Turton et al. 2005). Total abrogation of the gene function is reflected by the reported phenotype of the patients who were homozygous for the mutation.

The effect of a new change is somehow confusing. The phenotype of both probands clearly indicates genetic background, but uncommon manifestation suggests that an allele carrying the p.R112X change might potentially retain some residual protein activity. The functional core of the protein represents a DNA-binding homeodomain located between amino acids 68 and 130. The p.R112X mutation is placed directly in the homeodomain region and is terminating protein synthesis at the beginning of the third alpha helix (Fig. 4). Based on an in silico prediction of a reference and altered homeodomain orchestration, we noted that the residual amino acid sequence of p.R112X is identical to the corresponding part of the reference protein. The premature termination does not result in severe remodelling or misfolding of two proximal alpha helixes and, thus, this protein could potentially maintain some functionality. Because of the occurrence of a premature truncation codon at position 112, the NMD mechanism should also be regarded. However, the milder phenotype of the reported patients compared to carriers of i.e. homozygous c.150delA change indicates that this mechanism is not effective and, rather, does not result in substantial degradation of the abnormal c. 334C $>\mathrm{T}$ transcript (if it even occurs at all). An influence of other compensatory genetic or environmental mechanisms should also be considered, particularly in regards to other reports presenting a varying range of clinical manifestations, depending on the type of mutation (Kelberman and Dattani 2007; Mody et al. 2002).

The newly discovered alteration of the PROP1 gene is clinically relevant but the real spectrum of clinical consequences will be unveiled in patients with homozygous state. Both patients with gene mutations had definite thyroid hormones and probably GH and IGF-1 deficiency, starting in childhood; although they did not eventually attain a normal adult height, the presented skull dimensions and facial features were typical of non-affected adults. This may be explained by the modifying effect of thyroxine implemented early in the treatment on GH activity and its effect on bone growth (Do et al. 2015).

Similar clinical manifestation may appear in various PROP1 gene defects. This case is addressed to an early central hypothyroidism as a first symptom in CPHD patients with different defects: p.R99X(Q), p.R112X and p.S109X (Tatsumi et al. 2004; Voutetakis et al. 2004b; Wassner et al. 2013). In a substantial portion of CPHD cases, abnormalities in PROP1 and known CPHD-associated genes have not been identified. That implies an involvement of new genetic factors potentially contributing to the regulation of pituitary development and functioning, as an interesting target for further studies to be conducted. Furthermore, the constant improvement of genetic testing methods, i.e. whole-exome sequencing approach, that are more broadly employed for routine diagnostics will certainly facilitate the identification of CPHD cases at an earlier stage, even those with ambiguous course.

Acknowledgements The authors thank prof. Jerzy Kosowicz (Department of Endocrinology, Metabolism and Internal Diseases, Poznan University of Medical Sciences) for providing the archival data of patients and dr. Robert Kalak (Department of Biochemistry and Biotechnology, University of Agriculture) for the methodological support. We also thank the patients and all clinical staff participating in this study.

Compliance with ethical standards All procedures performed in studies involving human participants were in accordance with the ethical standards of the institutional and/or national research committee and with the 1964 Helsinki declaration and its later amendments or comparable ethical standards. The Bioethical Committee of Poznan University of Medical Sciences approved the study.

Funding This study was supported by grant no. P05B 10825 from the Polish State Committee for Scientific Research at the Ministry of Science and Higher Education and by the Polish National Science Center (DEC2012/04/M/NZ5/00475).

Conflict of interest The authors declare that they have no conflict of interest.

Informed consent Informed consent was obtained from all individual participants included in the study.

Open Access This article is distributed under the terms of the Creative Commons Attribution 4.0 International License (http:// creativecommons.org/licenses/by/4.0/), which permits unrestricted use, distribution, and reproduction in any medium, provided you give appropriate credit to the original author(s) and the source, provide a link to the Creative Commons license, and indicate if changes were made.

\section{References}

Andredaki M, Koumantanou A, Dorotheou D, Halazonetis DJ (2007) A cephalometric morphometric study of the sella turcica. Eur J Orthod 29:449-456. doi:10.1093/ejo/cjm048

Arroyo A, Pernasetti F, Vasilyev VV et al (2002) A unique case of combined pituitary hormone deficiency caused by a PROP1 gene mutation (R120C) associated with normal height and absent puberty. Clin Endocrinol 57:283-291

Böttner A, Keller E, Kratzsch J et al (2004) PROP1 mutations cause progressive deterioration of anterior pituitary function including adrenal insufficiency: a longitudinal analysis. J Clin Endocrinol Metab 89:5256-5265. doi:10.1210/jc.2004-0661 
Bushby KM, Cole T, Matthews JN, Goodship JA (1992) Centiles for adult head circumference. Arch Dis Child 67:1286-1287

Deladoëy J, Flück C, Büyükgebiz A et al (1999) "Hot spot” in the PROP1 gene responsible for combined pituitary hormone deficiency. J Clin Endocrinol Metab 84:1645-1650

Do A, Menon V, Zhi X et al (2015) Thyroxine modifies the effects of growth hormone in Ames dwarf mice. Aging 7:241-255

Flück C, Deladoey J, Rutishauser K et al (1998) Phenotypic variability in familial combined pituitary hormone deficiency caused by a PROP1 gene mutation resulting in the substitution of $\mathrm{Arg}->\mathrm{Cys}$ at codon 120 (R120C). J Clin Endocrinol Metab 83:3727-3734

Fofanova O, Takamura N, Kinoshita E et al (1998) Compound heterozygous deletion of the PROP-1 gene in children with combined pituitary hormone deficiency. J Clin Endocrinol Metab 83:2601-2604

Kelberman D, Dattani MT (2007) Hypopituitarism oddities: congenital causes. Horm Res 68(Suppl 5):138-144. doi:10.1159/000110610

Kelley LA, Sternberg MJ (2009) Protein structure prediction on the Web: a case study using the Phyre server. Nat Protoc 4:363-371. doi:10. 1038/nprot.2009.2

Kim SS, Kim Y, Shin YL, Kim GH, Kim TU, Yoo HW (2003) Clinical characteristics and molecular analysis of PIT1, PROP1, LHX3, and HESX1 in combined pituitary hormone deficiency patients with abnormal pituitary MR imaging. Horm Res 60:277-283

Lebl J, Vosáhlo J, Pfaeffle RW et al (2005) Auxological and endocrine phenotype in a population-based cohort of patients with PROP1 gene defects. Eur J Endocrinol 153:389-396. doi:10.1530/eje.1. 01989

Lemos MC, Gomes L, Bastos M et al (2006) PROP1 gene analysis in Portuguese patients with combined pituitary hormone deficiency. Clin Endocrinol (Oxf) 65:479-485. doi:10.1111/j.1365-2265.2006. 02617.x

McLennan K, Jeske Y, Cotterill A et al (2003) Combined pituitary hormone deficiency in Australian children: clinical and genetic correlates. Clin Endocrinol (Oxf) 58:785-794

Mody S, Brown MR, Parks JS (2002) The spectrum of hypopituitarism caused by PROP1 mutations. Best Pract Res Clin Endocrinol Metab $16: 421-431$

Pettersen EF, Goddard TD, Huang CC et al (2004) UCSF Chimera-a visualization system for exploratory research and analysis. J Comput Chem 25:1605-1612. doi:10.1002/jcc.20084

Riepe FG, Partsch CJ, Blankenstein O, Mönig H, Pfäffle RW, Sippell WG (2001) Longitudinal imaging reveals pituitary enlargement preceding hypoplasia in two brothers with combined pituitary hormone deficiency attributable to PROP1 mutation. J Clin Endocrinol Metab 86:4353-4357
Romero CJ, Pine-Twaddell E, Radovick S (2011) Novel mutations associated with combined pituitary hormone deficiency. J Mol Endocrinol 46:R93-R102. doi:10.1530/JME-10-0133

Rosenbloom AL, Almonte AS, Brown MR, Fisher DA, Baumbach L, Parks JS (1999) Clinical and biochemical phenotype of familial anterior hypopituitarism from mutation of the PROP1 gene. J Clin Endocrinol Metab 84:50-57

Schwarz JM, Rödelsperger C, Schuelke M, Seelow D (2010) MutationTaster evaluates disease-causing potential of sequence alterations. Nat Methods 7:575-576. doi:10.1038/nmeth0810-575

Schwede T, Kopp J, Guex N, Peitsch MC (2003) SWISS-MODEL: an automated protein homology-modeling server. Nucleic Acids Res 31:3381-3385

Sornson MW, Wu W, Dasen JS et al (1996) Pituitary lineage determination by the Prophet of Pit-1 homeodomain factor defective in Ames dwarfism. Nature 384:327-333. doi:10.1038/384327a0

Tatsumi KI, Kikuchi K, Tsumura K, Amino N (2004) A novel PROP1 gene mutation (157delA) in Japanese siblings with combined anterior pituitary hormone deficiency. Clin Endocrinol (Oxf) 61:635640. doi:10.1111/j.1365-2265.2004.02147.x

Turton JP, Mehta A, Raza J et al (2005) Mutations within the transcription factor PROP1 are rare in a cohort of patients with sporadic combined pituitary hormone deficiency (CPHD). Clin Endocrinol (Oxf) 63: 10-18. doi:10.1111/j.1365-2265.2005.02291.x

Voutetakis A, Livadas S, Sertedaki A, Maniati-Christidi M, DacouVoutetakis C (2001) Insufficient adrenarche in patients with combined pituitary hormone deficiency caused by a PROP-1 gene defect. J Pediatr Endocrinol Metab 14:1107-1111

Voutetakis A, Argyropoulou M, Sertedaki A et al (2004a) Pituitary magnetic resonance imaging in 15 patients with Prop1 gene mutations: pituitary enlargement may originate from the intermediate lobe. $\mathrm{J}$ Clin Endocrinol Metab 89:2200-2206

Voutetakis A, Maniati-Christidi M, Kanaka-Gantenbein C et al (2004b) Prolonged jaundice and hypothyroidism as the presenting symptoms in a neonate with a novel Prop1 gene mutation (Q83X). Eur J Endocrinol 150:257-264

Wassner AJ, Cohen LE, Hechter E, Dauber A (2013) Isolated central hypothyroidism in young siblings as a manifestation of PROP1 deficiency: clinical impact of whole exome sequencing. Horm Res Paediatr 79:379-386. doi:10.1159/000350013

Wu W, Cogan JD, Pfäffle RW et al (1998) Mutations in PROP1 cause familial combined pituitary hormone deficiency. Nat Genet 18:147149. doi:10.1038/ng0298-147

Yang Z, Lasker K, Schneidman-Duhovny D et al (2012) UCSF Chimera, MODELLER, and IMP: an integrated modeling system. J Struct Biol 179:269-278. doi:10.1016/j.jsb.2011.09.006 